\title{
Interaction of Flomazenil with Anxiolytic Effects of Citrus aurantium L. Essential Oil on Male Mice
}

\author{
Leila Adibi', Maryam Khosravi ${ }^{1}$, Shahrzad Khakpour ${ }^{2}$, Hedayat Sahraei ${ }^{3}$, \\ Mahsa Hadipour Jahromy ${ }^{2 *}$ \\ ${ }^{1}$ Biology Department, Faculty of Biological Sciences, Islamic Azad University North Tehran Branch, Tehran, Iran \\ ${ }^{2}$ Herbal Pharmacology Research Center, Tehran Medical Sciences Branch, Faculty of Medicine, Islamic Azad \\ University, Tehran, Iran \\ ${ }^{3}$ Neuroscience Research Center, Baghiatallah University of Medical, Tehran, Iran \\ Email: ${ }^{\text {jahromymh@yahoo.com }}$
}

Received 16 December 2014; accepted 3 February 2015; published 5 February 2015

Copyright (C) 2015 by authors and Scientific Research Publishing Inc.

This work is licensed under the Creative Commons Attribution International License (CC BY).

http://creativecommons.org/licenses/by/4.0/

c) (i) Open Access

\section{Abstract}

Due to our previous findings about the role of GABAegic neurotransmission in anxiolytic effects of Citrus aurantium L. essential oil, we are now presenting flomazenil interaction with this herb, as an antagonist of benzodiazepines at GABA receptor. The study was performed on 84 male albino mice assigned to 14 groups of six. The animals were injected intraperitoneally with the Citrus aurantium L. essential oil for 5 days. On the fifth day, either normal saline or flomazenil $(0.1 \mathrm{mg} / \mathrm{kg})$ was injected to the experimental groups. Thirty minutes after the injection, all the groups were assessed for anxiety-related behavior by elevated plus-maze test. In groups receiving Citrus aurantium $L$. essential oil at doses of 2.5 and 5 percent, the time spent in the open arms increased significantly $(P<0.001)$. The injection of flumazenil alone induced anxiety quite clearly observed by decreasing the time or number of entries in open arms. As an antagonist of benzodiazepines at GABA receptor, flomazenil acted as a competitive antagonist for Citrus aurantium L. essential oil regarding the increment in the number of entries to the open arms and the time spent in the open arms $(P<0.001)$ compared to flumazenil. It can then be concluded that Citrus aurantium L. essential oil induces its anxiolytic effects like benzodiazepines, in the same site at GABA receptor.

\section{Keywords}

Anxiety, Citrus aurantium L., Flomazenil

\footnotetext{
${ }^{*}$ Corresponding author.
}

How to cite this paper: Adibi, L., Khosravi, M., Khakpour, S., Sahraei, H. and Jahromy, M.H. (2015) Interaction of Flomazenil with Anxiolytic Effects of Citrus aurantium L. Essential Oil on Male Mice. Pharmacology \& Pharmacy, 6, 41-46. 


\section{Introduction}

Anxiety is common psychopathies that involve many persons [1]. Various neurotransmitter systems such as GABAergic, noradrenergic and serotonergic systems are responsible for anxiety symptoms [2]. GABA is the most important neurotransmitter in the brain affecting such behaviors as learning, pain, memory, paroxysm, and anxiety [3].

Anxiety occurs along with some biochemical changes and reactions in the brain such as increase in adrenalin (that quickens the heart beat) and reduction in dopamine (dopamine pain). Excessive anxiety makes the body ready for fight or running away.

It is normal to have some levels of anxiety in daily life which can be managed. An increase in levels of anxiety affects one's ability to enjoy life. Today, anxiety is considered one of the inability factors among the elderly [3].

The brain is the central organ for producing and coping with stress, because it establishes behavioral and physiological responses against stressors. In an adult, as the brain develops, the ability to cope with the stressors and responding to them also develops. Structural changes such as neuronal replacement, dendrite status change, and synopsis return are among brain responses features to the environment [4].

GABA as an important inhibitory neurotransmitter system plays a significant role, whether directly or indirectly, in neurological disorders. Among disorders that are affiliated with GABAA receptor, we can name anxiety, cognitive impairment, hysteria, mental disorder, schizophrenia, and sleep disorder (insomnia). GABA is a neurotransmitter system which can reduce anxiety with an inhibitory effect. It has been observed that stress increases glutamate in prefrontal cortex and hippocampus [5].

GABA hyperpolarizes post-synaptic neurons and has an important role in balancing excitation and neurons inhibition. Excessive inhibition or weak excitation will lead to coma, depression, reduction in blood pressure, calmness, and sleep. Excessive excitation or weak inhibition will lead to restlessness, anxiety, high blood pressure and insomnia. Disorders' symptoms depend on the region of the brain that is out of balance [6].

Many herbal medicines have been reported to pose anxiolytic effects.

Reasons to use southern (Shirazian) Citrus aurantium L. are that there are more alkanes in southern Citrus aurantium L. compared to the northern type. Besides an amount of aldehyde in the essential oil, a sign of the better quality of the product has been reported to be more in southern Citrus aurantium L.

There are oxides in northern Citrus aurantium L. essential oil, and not in the southern one. Also, alcoholic compounds in the northern oil are more frequent than those in the southern one. These compounds, because of having hydroxylic group, are able to make hydrogen bond with water. Therefore they bond with vapor drops and enter the water-cooler along with water and enter the essential oil after condensation. The findings also show that, oxygen monoterpenes, which are among aromatic hydrocarbons, are more frequent in northern Citrus aurantium $\mathrm{L}$. This sesquiterpene, which has anti-bacterial effects of terpenic hydrocarbons which are responsible for the aroma and healing effects of the essential oil, has a higher percentage in the southern essential oil. In sum, southern Citrus aurantium L. is richer in basic components of essential oil, so it has a better quality in terms of aroma [7].

\section{Materials and Methods}

This study was done on 84 male albino mice weighed $25 \mathrm{~g}$ supplied by Pasteur Institute. The mice were assigned to 14 groups of 6 for the experiment. The animals were kept in temperature of $22^{\circ} \mathrm{C}$ to $24^{\circ} \mathrm{C}$ with a $12 / 12$ hour light-dark cycle. Except for the actual time of the experiment, the mice had complete access to sufficient food and water. The study started after an acclimation period of 1 week. The terms and conditions of keeping laboratory animals were followed completely during the experiment.

\subsection{Preparation of the Essential Oil and the Medicine}

Collected Citrus aurantium L. flowers were dried and then grinded by an electric mill. $300 \mathrm{~g}$ of the dried powder of Citrus aurantium L. were put in a $1000 \mathrm{cc}$ balloon and distilled water was added to make up the volume to $1000 \mathrm{cc}$. Next, the balloon was put on the heater and connected to the Clevenger apparatus for 2 hours. 2 drops of n-hexane was added to the tube. Essential oil, which was yellow in color and had a strong odor, was then collected and dewatered using sodium sulfate. The vials were completely covered by aluminum foil and kept in a 
cool place. The essential oil using olive oil was obtained at different densities of $0.5,2.5$, and 5 percent.

Flomazenil ( $1 \mathrm{mg} / \mathrm{kg}$ ) was supplied by Kimiadarou Company. Flomazenil was injected using saline sterile $9 \%$ (normal saline).

\subsection{Method}

After an acclimation period of 1 week, the animals were injected intraperitoneally with the Citrus aurantium L. essential oil at a certain hour for 5 days. On the fifth day and thirty minutes before applying Citrus aurantium L. essential oil, flomazenil $(0.1 \mathrm{mg} / \mathrm{kg})$ was injected to the experimental groups. Thirty minutes after the injection, all the groups were assessed for anxiety-related behavior by elevated plus-maze test.

\section{Findings}

Figure 1 shows how the intraperitoneal injection of the essential oil of Citrus aurantium L. (at doses of 0.5, 2.5, and 5 percent) resulted in the increase of the time spent in the open arms. In terms of the time spent in the open arms, there was a significant difference between the groups that were injected with doses of 2.5 and 5 percent and the control groups $(\mathrm{P}<0.001)$

Figure 2 shows that the intraperitoneal injection of the essential oil of Citrus aurantium L. (at doses of 0.5, 2.5 , and 5 percent) does not make a significant difference in the number of entries to open arms, although the number of the entries to open arms in recipient groups of $2 / 5$ and 5 percent of doses was higher than the 0.5 percent group.

Figure 3 shows that the intraperitoneal injection of flomazenil as compared to the control and sham leads to a significant reduction in the time spent on open arms.

Figure 4 shows that the intraperitoneal injection of flomazenil $(1 \mathrm{mg} / \mathrm{kg})$ leads to a significant reduction in the number of open arms as compared to the control group $(\mathrm{p}<0.001)$. Applying flomazenil and Citrus aurantium $\mathrm{L}$. at doses of $0.5,2.5$, and 5 percent simultaneously leads to an increase in the number of entries to the open arms with flomazenil group $(\mathrm{p}<0.01)$ and $(\mathrm{p}<0.001)$.

\section{Discussion}

The results of this study show that essential oil of Citrus aurantium L., in terms of applied dose, can reduce the anxiety in mice significantly. Sedative and anti-anxiety effects of this plant have been mentioned in previous studies [8]. It is possible that these effects are the result of an interaction with GABAergic pathways and subsequent impacts on GABAA receptors. One of the essential compounds of Citrus aurantium L. is limonene which reduces the activity of neurons in central nervous system [8]. After researching the brain, limonene attaches itself

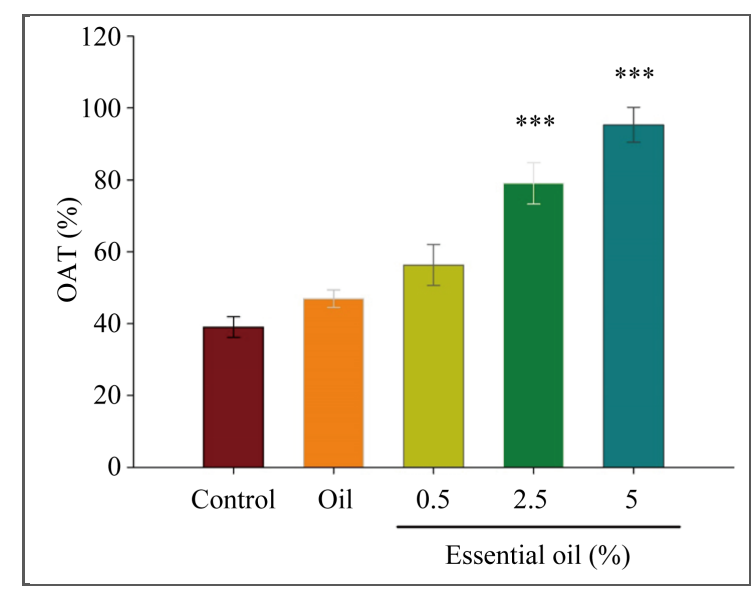

Figure 1. Comparison between experimental group (received essential oil of Citrus aurantium L. at doses of $0.5,2.5$, and 5 percent), control group and sham group (received olive oil) in anti-anxiety effect of $\mathrm{Ci}$ trus aurantium L. essential oil. Mean \pm S.E.M. $\mathrm{n}=7$. $* * * \mathrm{P}<0.001$ versus control and sham groups. OAT is the spent time in open arms. 


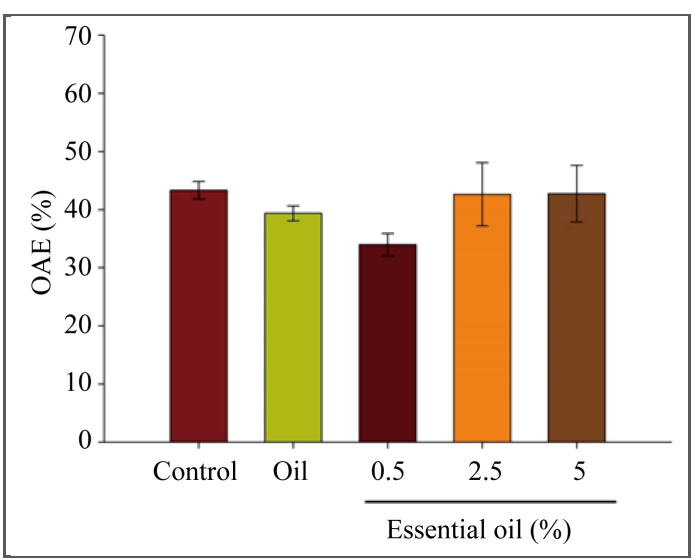

Figure 2. Comparison between experimental group (received essential oil of Citrus aurantium L. at doses of $0.5,2.5$, and 5 percent), control group and sham group (received olive oil) in anti-anxiety effect of $\mathrm{Ci}$ trus aurantium L. essential oil. Mean \pm S.E.M. $\mathrm{n}=6$.

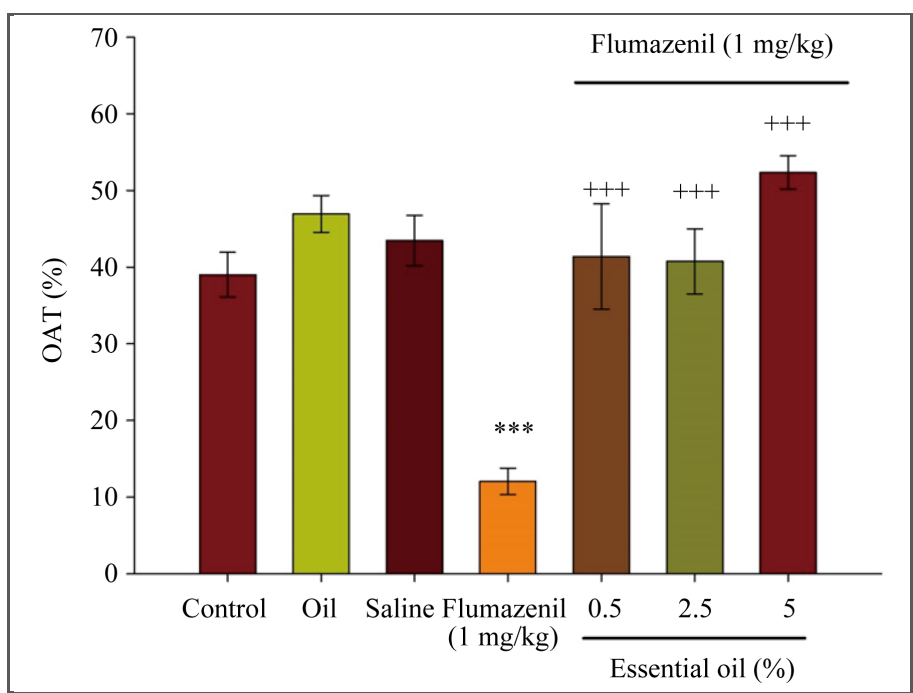

Figure 3. Effect of Citrus aurantium L. essential oil in experimental groups (received essential oil of Citrus aurantium L. at doses of 0.5, 2.5, and 5 percent), control and sham group (received olive oil), flomazenil and its combination with essential oils on the percent of time spent in open arms. Mean \pm S.E.M. $\mathrm{n}=6 . * * * \mathrm{P}<0.001$ versus control and sham groups. $+\mathrm{P}<0.05$ versus flomazenil group. OAT $\%$ is the percent time spent in open arms.

to GABAA receptors and reduces anxiety-related activities [8]. Another study shows how limonene, by acting on GABAA receptors, increases the density of gamma-aminobutyric acid and reduces stress [9]. Limonene is therefore one of the compounds in Citrus aurantium L. which has anti-anxiety effects.

Coumarin is another compound in Citrus aurantium L. which has similar sedative effects. A study done by Pereira (2009) demonstrates how acute administration of coumarin to prefrontal cortex and hippocampus of mice can help preventing seizures by effecting GABAA receptors and therefore releasing more gamma-aminobutyric acid in prefrontal cortex. Linalool is also another compound in Citrus aurantium L. which exert inhibitory effects in the nervous system through pre-synaptic inhibition and prevention of acetylcholine release [10]. Linalool is a competitive antagonist for glutamate receptors; consequently, by blocking these receptors, it reduces the effect of this neurotransmitter system and prevents epileptic and anxiety-related fits [11].

In this study flomazenil $(1 \mathrm{mg} / \mathrm{kg})$ was used as the antagonist of GABA receptors. Flomazenil reverses the 


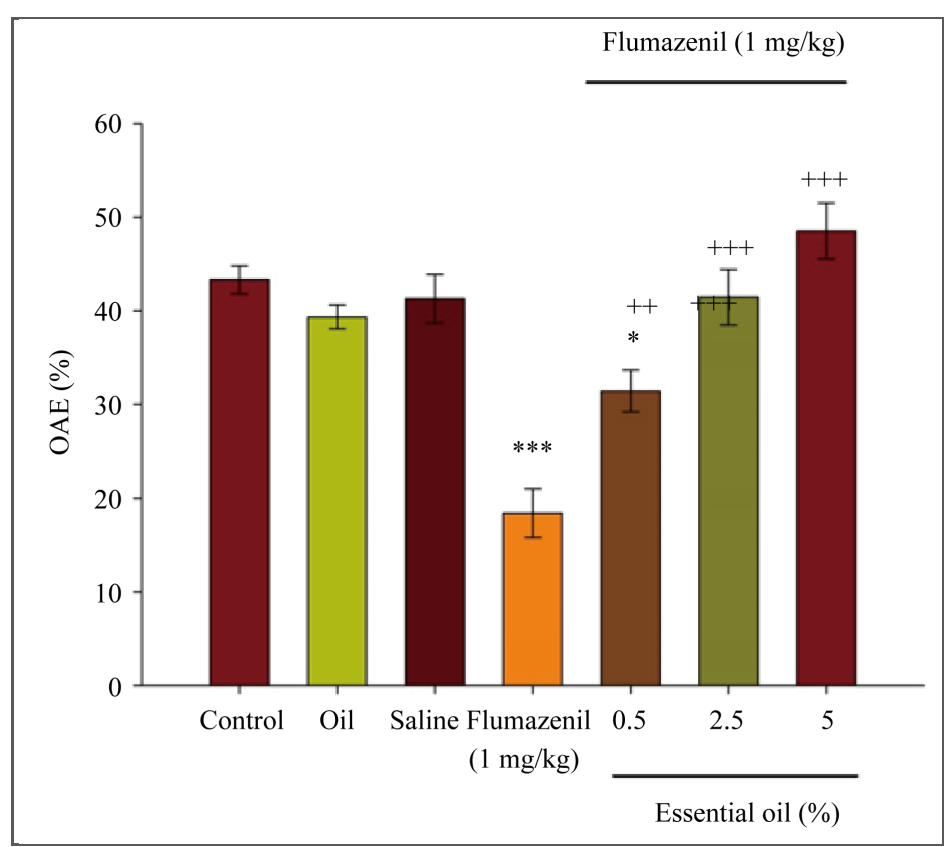

Figure 4. Effect of Citrus aurantium L. essential oil in experimental groups (received essential oil of Citrus aurantium L. at doses of 0.5, 2.5, and 5 percent), control and sham group (received olive oil), flomazenil and its combination with essential oils on the percent of number of entries in open arms. Mean \pm S.E.M. $\mathrm{n}=6$. Mean \pm S.E.M. $\mathrm{n}=6$. $* * * \mathrm{P}<0.001$ versus control and sham groups. $+\mathrm{P}<0.05$ versus flomazenil group. $\mathrm{OAE} \%$ is the number of entries in open arms.

inhibition effect of benzodiazepines by competing them [12]. Flomazenil leaves its antagonistic effect by attaching on the benzodiazepines on GABA receptors [13].

Flomazenil antagonizes the benzodiazepine effects in the central nervous system, but it is not able to antagonize the effects of the medicines which are effective on the GABAergic neurons. Also flomazenil is not able to reverse the epioids effects [13]. Some evidences show that flomazenil separates benzodiazepine from the receptor. Flomazenil attachment to the benzodiazepine place on the receptor will lead to a change in the receptors sensitivity and changes the receptors attachment tendency to benzodiazepines [13]. The intraperitoneal injection of flomazenil increases the anxiety behavior of the mice and reduces the time spent on open arms and time of the open arms entry.

In this study, simultaneous injection of Citrus aurantium L. essential oil and flomazenil leads to inhibition of flomazenil effect and an increase in the open arms entry and staying in open arms.

\section{Conclusion}

It can then be concluded that Citrus aurantium L. essential oil induces its anxiolytic effects like benzodiazepines, in the same site at GABA receptor due to the blockade of its anxiolytic effects by flomazenil.

\section{References}

[1] Bueno, C.H., Zangrossi Jr., H. and Viana, M.B. (2005) The Inactivation of the Basolateral Nucleus of the Rat Amygdala Has an Anxiolytic Effect in the Elevated T-Maze and Light/Dark Transition Tests. Brazilian Journal of Medical and Biological Research, 38, 1697-1701. http://dx.doi.org/10.1590/S0100-879X2005001100019

[2] Zarrindast, M.R., Torabi, M., Rostami, P. and Fazli-Tabaei, S. (2006) The Effects of Histaminergic Agents in the Dorsal Hippocampus of Rats in the Elevated Plus-Maze Test of Anxiety. Pharmacology Biochemistry and Behavior, 85, 501-506. http://dx.doi.org/10.1016/j.pbb.2006.09.019

[3] Andreasen, N.C. (2004) Acute and Delayed Posttraumatic Stress Disorder: A History and Some Issues. American Journal of Psychiatry, 161, 1321-1323. http://dx.doi.org/10.1176/appi.ajp.161.8.1321 
[4] Gray, J.A. and McNaughton, N. (2000) The Neuropsychology of Anxiety. 2nd Edition, Oxford Medical Publications, Oxford.

[5] Taylor, M, Bhagwagar, Z., Cowen, P.J. and Sharp, T. (2003) GABA and Mood Disorders. Psychological Medicine, 33, 3873-3893. http://dx.doi.org/10.1017/S0033291702006876

[6] Chebib, M. and Johnston, G.A.R. (2000) GABA-Activated Ligand Gated Ion Channels: Medicinal Chemistry and Molecular Biology. Journal of Medicinal Chemistry, 43, 1427-1447. http://dx.doi.org/10.1021/jm9904349

[7] Carvalho-Freitas, M.I. and Costa, M. (2002) Anxiolytic and Sedative Effects of Extracts and Essential Oil from Citrus aurantium L. Biological \& Pharmaceutical Bulletin, 25, 1629-1633. http://dx.doi.org/10.1248/bpb.25.1629

[8] Re, L., Barocci, S., Sonnino, S., et al. (2000) Linalool Modifies the Nicotinic Receptor-Ion Channel Kinetics at the Mouse Neuromuscular Junction. Neurochemical Research, 42, 177-181.

[9] Silva Brum, L.F., Emanuelli, T., Souza, D.O., et al. (2001) Effects of Linalool on Glutamate Release and Uptake in Mouse Cortical Synaptosomes. Neurochemical Research, 26, 191-194. http://dx.doi.org/10.1023/A:1010904214482

[10] Fuster, J.M. (2000) The Prefrontal Cortex-An Update: Time Is of the Essence. Neuron, 30, 319-333. http://dx.doi.org/10.1016/S0896-6273(01)00285-9

[11] Johnston, G.A.R. (2005) GABA A Receptor Channel Pharmacology. Current Pharmaceutical Design, 11, $1867-1885$. http://dx.doi.org/10.2174/1381612054021024

[12] Lader, M.B. and Morton, S.V. (1992) A Pilot Study of the Effects of Flumazenil on Symptoms Persisting after Benzodiazepine Withdrawal. Journal of Psychopharmacology, 6, 19-28. http://dx.doi.org/10.1177/026988119200600303

[13] Votey, S.R., Bosse, G.M., Bayer, M.J. and Hoffman, J.R. (1991) Flumazenil: A New Benzodiazepine Antagonist. Annals of Emergency Medicine, 20, 181-188. http://dx.doi.org/10.1016/S0196-0644(05)81219-3 
Scientific Research Publishing (SCIRP) is one of the largest Open Access journal publishers. It is currently publishing more than 200 open access, online, peer-reviewed journals covering a wide range of academic disciplines. SCIRP serves the worldwide academic communities and contributes to the progress and application of science with its publication.

Other selected journals from SCIRP are listed as below. Submit your manuscript to us via either submit@scirp.org or Online Submission Portal.
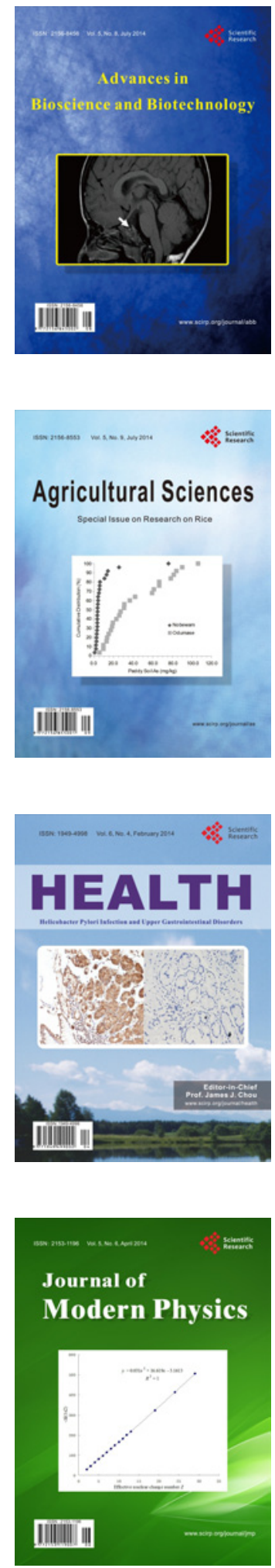
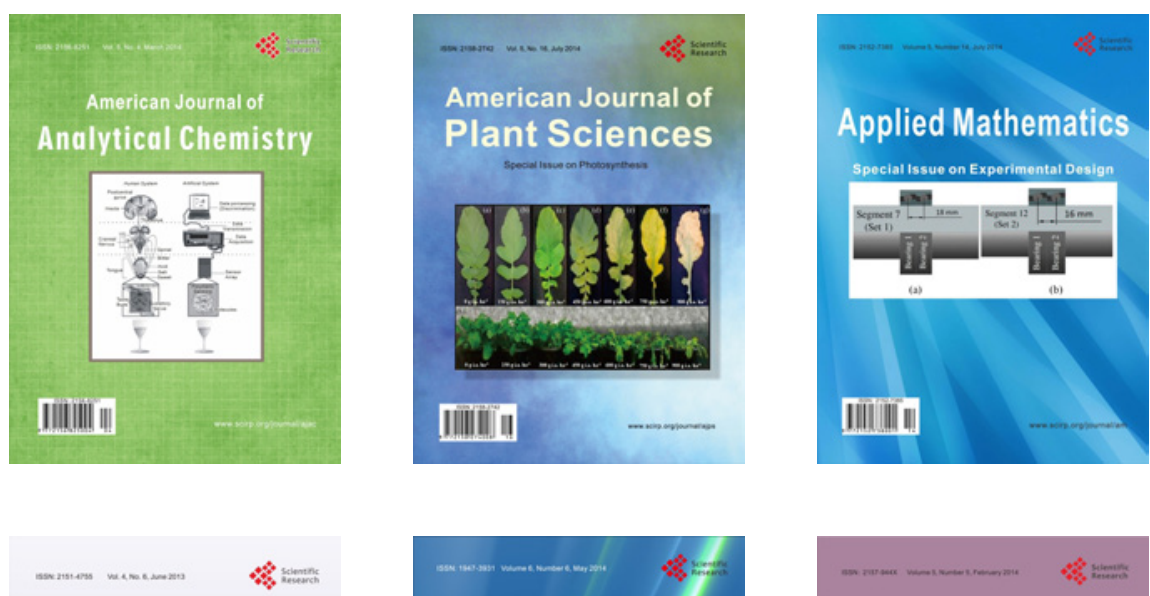

Creative Education
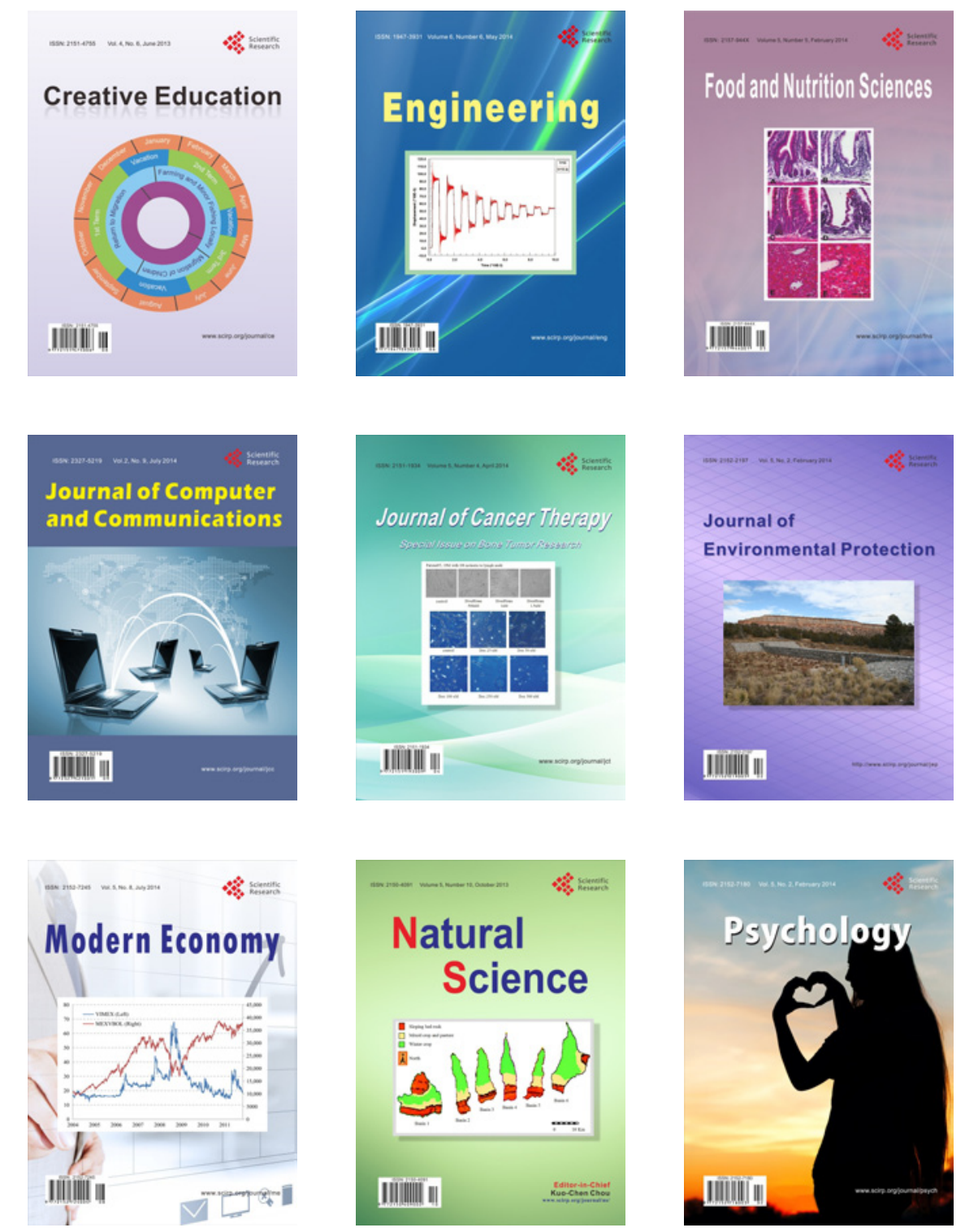